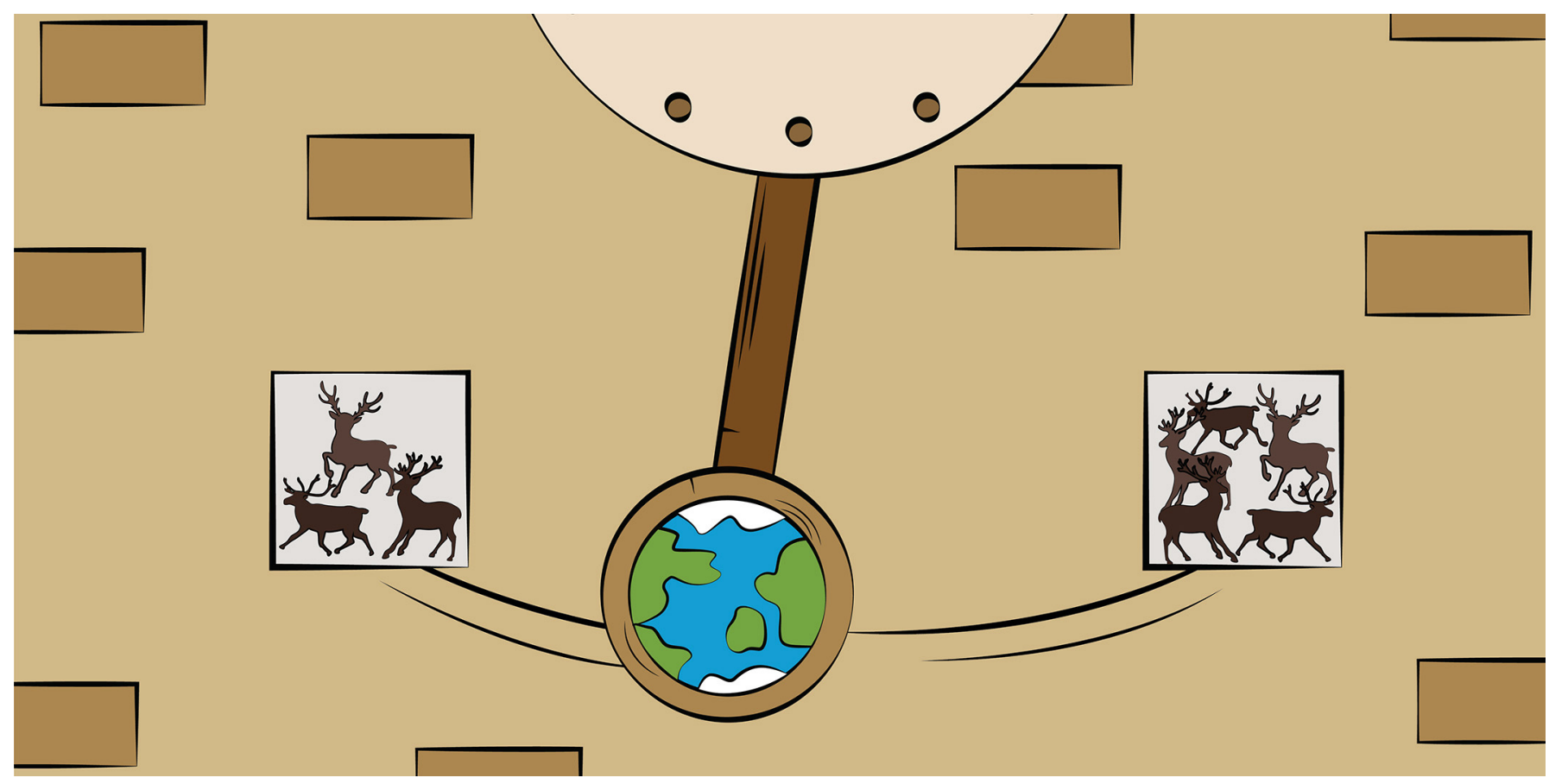

\title{
WHAT GOES UP MUST COME DOWN: THE INFLUENCE OF CLIMATE ON CARIBOU POPULATIONS
}

\section{Kyle Joly *}

Gates of the Arctic National Park and Preserve, National Park Service, Fairbanks, AK, United States

YOUNG REVIEWERS:

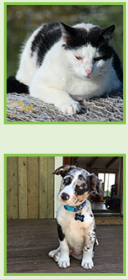

ALESSANDRO

AGE: 14

LUCY

AGE: 14

\section{OSCILLATION}

An endless, rhythmic pattern ranging from low to high.
Wildlife populations naturally go up and down. Oscillation is the term used for this pattern of highs (when there are many animals) and lows (when there are few). When the number of births is greater than the number of deaths, then populations grow. If deaths exceed births, populations decline. Caribou in the Arctic have dramatic population oscillations. The number of caribou can grow very high and also decrease to very few. Large-scale, long-lasting weather oscillations are one reason for this pattern. Knowledge of the connection between wildlife populations and climate oscillations is important to help conserve species like caribou and to better understand how climate change will impact wildlife.

\section{INTRODUCTION}

Caribou are a member of the deer family that live in northern regions across the world (Figure 1). They are well-known for their dramatic population oscillations [1]. An oscillation is a rhythmic pattern of low-to-high population numbers and back again, continuing endlessly 
Figure 1

Male (bull) caribou in Kobuk Valley National Park, Alaska, during their fall migration (Photo credit: Kyle Joly, NPS).

\section{POPULATION}

\section{CRASH}

A rapid decline in the number of animals.

\section{BOTTOM-UP}

\section{FACTOR}

An influence coming from food items, like plants at the bottom of the food chain, that influence animal populations. They are often dependent on the number (density) of animals.

\section{TOP-DOWN}

FACTOR

An influence coming from predators, animals at the top of the food chain.

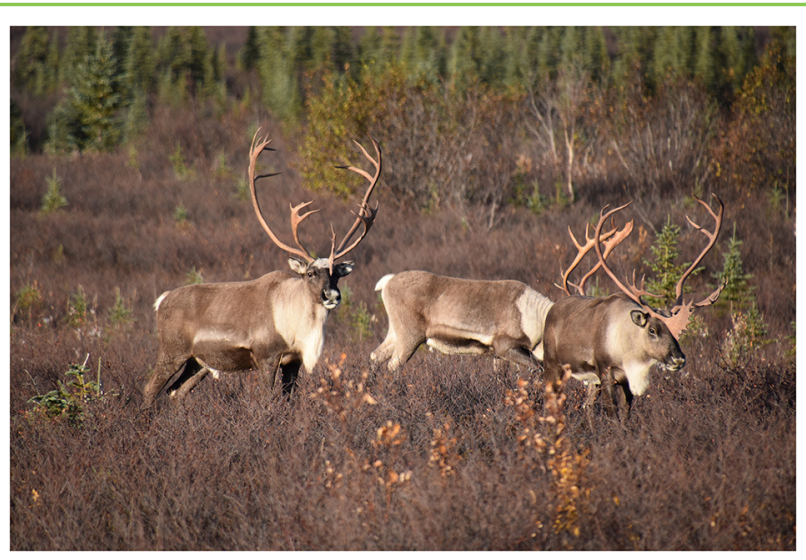

Figure 1

(Figure 2). Within just a few years, Arctic caribou herds can number in the hundreds of thousands of animals, but then decline by half or even much more. This is often referred to as a population crash. Upon reaching a population low, caribou herds can sharply rebound and grow quickly.

The math behind oscillations is quite simple: if there are more births than deaths, then the population goes up. If there are more deaths than births, then the population goes down. But the factors that drive population increases or decreases can be quite complicated.

\section{WHAT DRIVES CARIBOU POPULATION OSCILLATIONS?}

If the number of births and deaths in a herd determines population oscillations, what determines the number of births and deaths? The number of births depends on the number of adult females in the herd and their physical condition. The bigger the herd, the more females there are and the greater potential for more births. For females to get pregnant, they must be in good enough condition. Body condition is determined by the quality and quantity of food. When the herd is very large, the potential number of births is high, but, at the same time, there is more competition for food. When there is more competition for food, the body condition of females can decline and not as many will give birth. This is what is called a bottom-up factor. It is called bottom-up because it is dependent on the bottom of the food chain: plants, which are food for caribou. Deaths can come from a wide range of causes. Caribou are eaten by predators, like gray wolves and brown bears, or hunted by humans for food. Predation is a top-down factor because the impact is coming from a higher level in the food chain. Caribou can also contract diseases, suffer malnutrition, and die in accidents, like avalanches or drownings. Accidents are random factors that are not driven by the food chain and can affect any individual. All these factors can make caribou population numbers decline. Bottom-up factors tend to be more important during population highs 
Figure 2

An illustration of oscillations. The y(vertical) axis shows the size (for example, the number of animals in a population) and the $x$ (horizontal) axis represents time. The amount of time between peaks is known as the period of the oscillation. The height of the increase is known as the amplitude of the oscillation.

\section{PACIFIC DECADAL}

\section{OSCILLATION}

A persistent, large-scale weather pattern centered in the northern Pacific Ocean

\section{CLIMATE}

Weather patterns over a long period of time.

\section{LICHENS}

An organism made up of fungi combined with algae and/or bacteria. Lichens often grow on rocks, tree bark, or the ground.

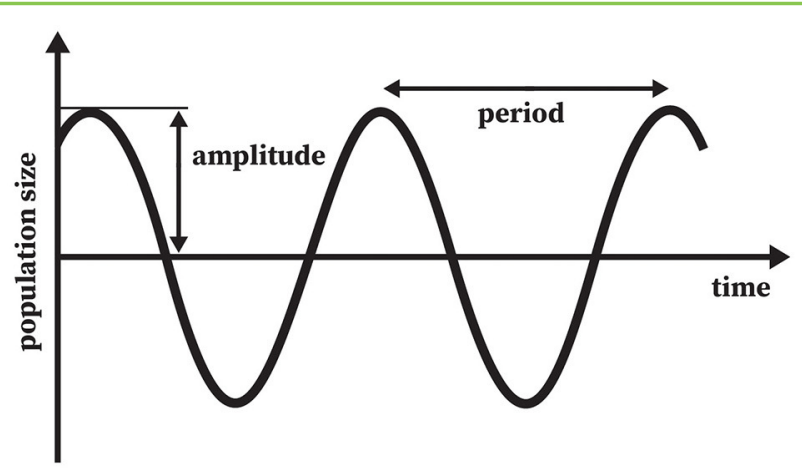

Figure 2

and top-down factors more important during population lows. When the population is low, there is less competition for food and animals can improve their body condition. Then pregnancy rates increase, and the oscillation cycle starts all over.

\section{OSCILLATIONS IN CLIMATE}

Wildlife populations are not the only things that oscillate. There are large-scale weather patterns that oscillate, too. The most famous of these oscillations is El Niño/La Niña, known to scientists as El Niño-Southern Oscillation. Changes in water temperatures on the ocean surface affect air pressure, which affects the weather over large areas of the planet. El Niño is the warm phase, and La Niña is the cold phase [2]. This oscillation is centered in the southern Pacific Ocean. In the northern Pacific, there is a similar phenomenon called the Pacific Decadal Oscillation, or PDO. The PDO can strongly influence the climate of Alaska. As its name suggests, the PDO has a long lifespan, with oscillations lasting decades [3,4]. The PDO has a positive (or warm) phase and a negative (or cold) phase, which bring with them changes in both temperature and the amount of precipitation.

\section{LINKING CARIBOU POPULATION AND CLIMATE OSCILLATIONS}

Changes in weather, such as temperature and precipitation, impact plant growth. More plant growth equals more caribou food. But the amount and type of precipitation (rain or snow) determines how difficult it is for caribou to get to their food. Deep snow or ice layers can make it hard for caribou to dig down to ground-growing food like lichens. Lichens make up more than $70 \%$ of the diet of caribou in late fall and winter [5]. Thus, it makes sense that there could be a connection between climate oscillations (like the PDO) and caribou population oscillations. The largest caribou herd in Alaska is the Western Arctic Herd, which ranges over five national parks. This herd can have as many as 500,000 animals during its population 
Figure 3

Relationship between the Western Arctic herd population oscillations (black line) and the large-scale climate oscillation known as the Pacific decadal oscillation (PDO; colored bars). The herd tends to increase when PDO values are positive (when it is warmer and wetter) and decline when they are negative (when it is colder and drier). These data tell us that when the PDO is positive, the herd tends to grow (green bars) and declines when the PDO is negative (red bars).

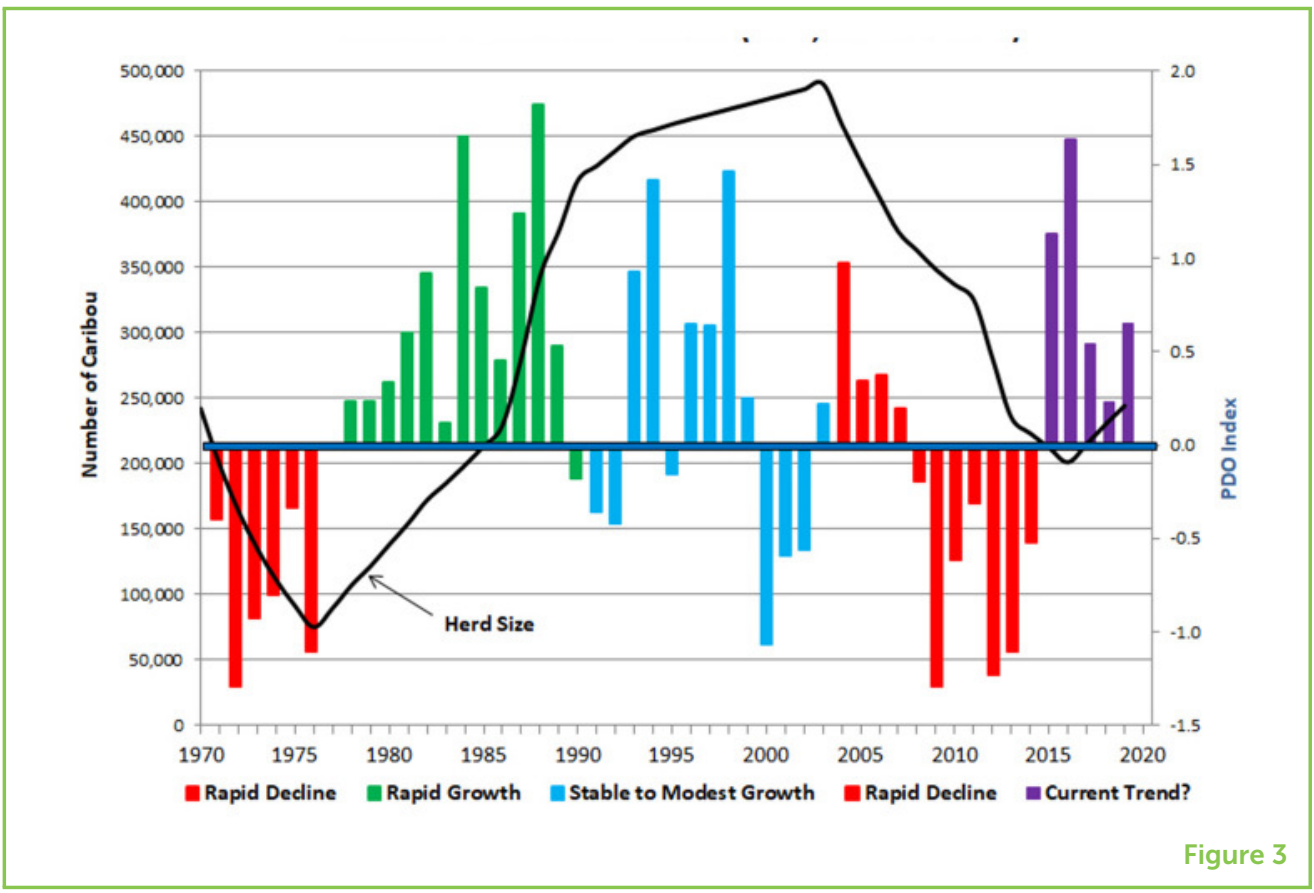

highs. An analysis looking at the swings in the PDO and the Western Arctic Herd showed that these two oscillations appear to be linked (Figure 3) [1].

\section{CONCLUSION}

The relationships between animals and the environments in which they live can be quite complicated. Changes in ocean temperatures can affect the weather over long periods of time and huge areas. Weather impacts the bottom of the food chain (plants), which are food for caribou. More and higher-quality food can allow caribou to survive longer and produce more offspring, increasing the population. Less or poorer-quality food can reduce caribou body condition, decreasing population by lowering survival and birth rates. Food availability is also related to the number of caribou. When populations are high, there is more competition for food. Although there are many factors that impact population size, weather and climate are important to Arctic caribou. Understanding the relationship between weather and wildlife populations is important to help conserve them in a time when the climate is changing rapidly.

\section{ACKNOWLEDGMENTS}

I thank collaborators and scientists with the Alaska Department of Fish and Game, National Park Service, and University of Alaska-Fairbanks for helping to make this work possible. I thank L. Weaver for creating Figure 2. Two Young Reviewers provided thoughtful and constructive 
suggestions that greatly improved the final version of this article. Funding was provided by the National Park Service.

\section{REFERENCES}

1. Joly, K., Klein, D. R., Verbyla, D. L., Rupp, T. S., and Chapin, F. S. 2011. Linkages between large-scale climate patterns and the dynamics of Alaska caribou populations. Ecography. 34:345-52. doi: 10.1111/j.1600-0587.2010. 06377.x

2. Grimm, A. M., Barros, V. R., and Doyle, M. E. 2000. Climate variability in southern South America associated with El Niño and La Niña events. J Clim. 13:35-58. doi: 10.1175/1520-0442(2000)013<0035:CVISSA > 2.0.CO;2

3. Hartmann, B., and Wendler, G. 2005. The significance of the 1976 Pacific climate shift in the climatology of Alaska. J Clim. 18:4824-39. doi: 10.1175/JCLI3532.1

4. Mantua, N. J., Hare, S. R., Zhang, Y., Wallace, J. M., and Francis, R. C. 1997. A Pacific interdecadal climate oscillation with impacts on salmon production. Bull Am Meteorol Soc. 78:1069-79.

5. Joly, K., and Cameron, M. D. 2018. Early fall and late winter diets of migratory caribou in northwest Alaska. Rangifer. 38:27-38. doi: 10.7557/2.38.1.4107

SUBMITTED: 19 November 2020; ACCEPTED: 01 December 2021; PUBLISHED ONLINE: 17 December 2021.

EDITED BY: Erin Kathleen Shanahan, National Park Service, United States

CITATION: Joly K (2021) What Goes Up Must Come Down: The Influence of Climate on Caribou Populations. Front. Young Minds 9:631372. doi: 10.3389/frym. 2021.631372

CONFLICT OF INTEREST: The author declares that the research was conducted in the absence of any commercial or financial relationships that could be construed as a potential conflict of interest.

COPYRIGHT (c) 2021 Joly. This is an open-access article distributed under the terms of the Creative Commons Attribution License (CC BY). The use, distribution or reproduction in other forums is permitted, provided the original author(s) and the copyright owner(s) are credited and that the original publication in this journal is cited, in accordance with accepted academic practice. No use, distribution or reproduction is permitted which does not comply with these terms.

\section{YOUNG REVIEWERS}

\section{ALESSANDRO, AGE: 14}

$\mathrm{Hi}$, my name is Alessandro in Belgrade where I live and work on our family ranch with my brother. I play hockey and love the outdoors. Some activities I enjoy are hiking, fishing and sledding. My favorite subject in school is engineering and my least favorite is math. I love constructing Lego trains and tracks. My favorite season is summer. In addition to our cattle, we have 17 horses, 2 cats, a fish, and a dog. 


\section{LUCY, AGE: 14}

I am 14 years old; I live in Montana and am in 8th grade. I enjoy playing soccer and basketball, ski, and mountain bike. I also love being outside and playing with our dog! I got involved because I love helping my dad with his work and hope to be a biologist one day.

\section{AUTHOR}

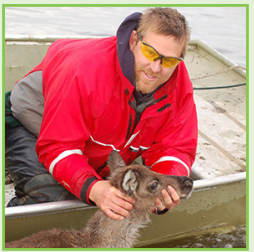

\section{KYLE JOLY}

Kyle Joly is a National Park Service wildlife biologist. He works in all the northern Alaska national parks, researching and monitoring caribou, wolves, grizzly bears, moose, Dall's sheep, and other interesting Alaskan critters. In this photo, he is capturing a caribou calf that was swimming across the Kobuk River in Kobuk Valley National Park, Alaska, during its fall migration. Learn more at https://www.nps.gov/articles/kyle-joly-wildlife-biologist.htm. *kyle_joly@nps.gov 